\title{
Variations of multi-parameter observations in atmosphere related to earthquake
}

\author{
F. Jing ${ }^{1}$, X. H. Shen ${ }^{1}$, C. L. Kang ${ }^{2}$, and P. Xiong ${ }^{1}$ \\ ${ }^{1}$ Institute of Earthquake Science, China Earthquake Administration, Beijing, China \\ ${ }^{2}$ China Earthquake Networks Center, China Earthquake Administration, Beijing, China
}

Correspondence to: F. Jing (jennyfer1111@163.com)

Received: 11 January 2012 - Revised: 19 November 2012 - Accepted: 20 November 2012 - Published: 9 January 2013

\begin{abstract}
Anomalies of multi-parameters (outgoing longwave radiation, surface latent heat flux, air temperature, relative humidity, and air pressure) before the 12 May 2008 Wenchuan $M_{\mathrm{S}}=8.0$ earthquake were discussed in order to obtain the seismic precursors. Multi-parameter data were computed based on multi-year background data. The results indicated that these parameters had significant variations prior to this event. The anomaly of outgoing longwave radiation was observed firstly, which gives an early warning. Next were air temperature, relative humidity, and air pressure, which had quasi-simultaneous variations in the basin and the mountain region close to the epicenter. The last was surface latent heat flux, which happened the day before this event. The characteristics of the parameter variations for this event are similar to other earthquakes, which is demonstrated in some other publications. The variations can be attributed to solid earth degassing and chemical reactions in the atmosphere. Additionally, the emission of gases from solid earth into the atmosphere could be ascribed to the tectonic stress of the Wenchuan earthquake.
\end{abstract}

\section{Introduction}

The earthquake precursors at different heights over the seismogenic region and prior to the seismic events have been observed by satellite remote sensing techniques. The precursors can be classified into three groups based on their elevation. The first category occurred on the surface, such as land surface temperature (Panda et al., 2007). The second occur in the atmosphere such as outgoing longwave radiation (Liu et al., 1997), surface latent heat flux (Singh et al., 2007), and air temperature (Tronin et al., 2004). Lastly, some others occur in the ionosphere, such as total electron content (Liu et al., 2004).

In this paper we analyzed the changes in the multiple parameters of the atmosphere, including outgoing longwave radiation (OLR), surface latent heat flux (SLHF), air temperature (AT), air relative humidity (ARH), and air pressure (AP). It has been proven that these parameters will change before strong earthquakes (e.g. Colima $M=7.8$, Michoacan $M=8.1$, Hector Mine $M=7.1$, Parkfield $M=6$ ) (Pulinets et al., 2007).

It is worth mentioning that OLR variation has been investigated in detail because it can reflect the energy variation in the earth-atmosphere system and records the earthquake thermal anomalies in different time scales over the seismic monitoring field (Liu et al., 2000, 2003; Ouzounov et al., 2007; Kang et al., 2008; Jing et al., 2009; Xiong et al., 2010). Therefore, it became one of the multiple ways to carry out earthquake prediction in China's earthquake prediction department. However, the mechanism of earthquake preparation is still unclear, which is a block to earthquake prediction, especially short-term earthquake prediction. The comprehensive analysis of multi-parameters is helpful to enhance the reliability of seismic anomalies identification, and understanding of the seismic anomalies mechanism.

The Wenchuan $M_{\mathrm{s}}=8.0$ earthquake of 12 May 2008 is the strongest earthquake since the 1976 Tangshan $M_{\mathrm{S}}=7.8$ earthquake in China's mainland. The epicenter was located at $31.01^{\circ} \mathrm{N}, 103.42^{\circ} \mathrm{E}$, and the depth was $14 \mathrm{~km}$ (according to China Seismic Network). This paper focused on the changes in the multiple parameters (OLR, SLHF, AT, AP, and $\mathrm{ARH}$ ) and showed the behavior of multi-parameters prior to the Wenchuan earthquake. The thermal dynamic process during the seismic preparation and the physical mechanism of 


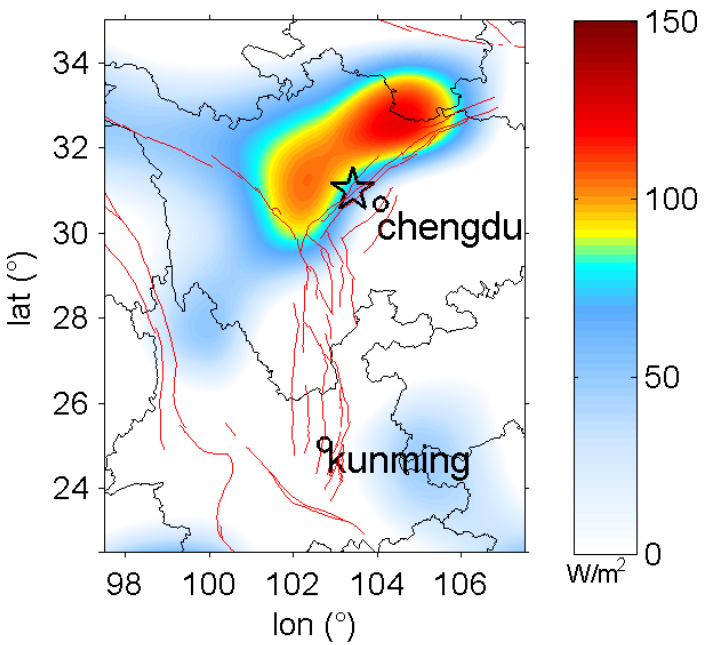

Fig. 1. Accumulative monthly OLR variations over SichuanYunnan region in 2007 (epicenter is marked with star, active faults with red lines).

the variations in atmospheric parameters related to this earthquake were discussed preliminarily.

\section{Data and results}

We have collected multi-parameter data (OLR, SLHF, AT, $\mathrm{AP}$, and $\mathrm{ARH}$ ), pre- and post-Wenchuan earthquake, from NOAA (National Oceanic and Atmospheric Administration, USA) and NCEP (National Centers for Environmental Prediction, USA). The results of our analyses are described in the following sections.

\subsection{Outgoing longwave radiation (OLR)}

OLR is the emission to space of terrestrial radiation from the top of the Earth's atmosphere, it is controlled by the temperature of the earth and the atmosphere above it, the water vapor in the atmosphere, and the clouds. The OLR dataset we used is estimated from the radiance in the $10-12 \mu \mathrm{m}$ infrared windows observed by NOAA polar-orbiting satellites, and computed to $2.5^{\circ} \times 2.5^{\circ}$ or $1.0^{\circ} \times 1.0^{\circ}$ (latitude $\times$ longitude) grids by the National Environmental Satellite Data and Information Service (NESDIS) USA. The algorithm's description of interpolation can be found in related reference (Liebmann, 1996). One can download it from the website of NOAA Climate Prediction Center.

Based on the multi-year (1979-2008) background data (the mean value deducting the background value), we computed the $2.5^{\circ} \times 2.5^{\circ}$ accumulative OLR monthly variations over the seismogenic region in 2007 based on twelve-month data (Fig. 1). One can see that the highest variation of OLR was distributed along the seismogenic structure (Longmenshan active fault). It is an indication of the energy accumulation along this fault.
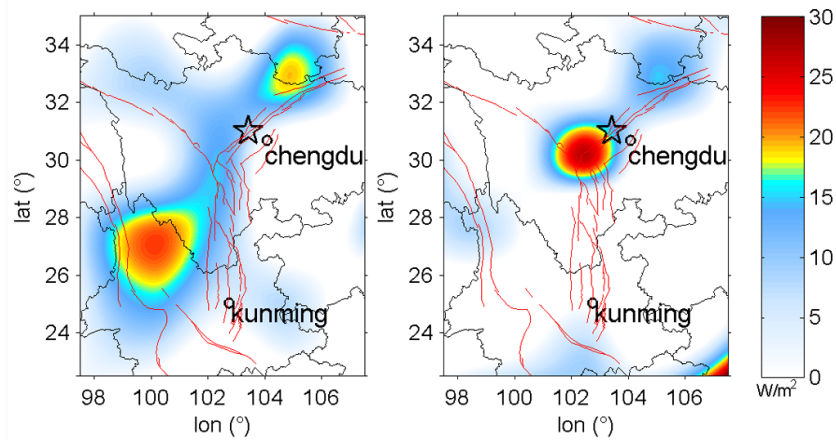

Fig. 2. OLR variation over Sichuan-Yunnan region in April (left) and May (right), 2008 (epicenter is marked with star, active faults with red lines).

The OLR monthly-data have been analyzed. We found anomalous OLR variation is near the eastern boundary of the Qinghai-Tibetan Plateau, and that the two highest values are on the north and south of this boundary on April 2008. After that, the largest variation transfered to the south of the Longmenshan fault during the month of the main shock (Fig. 2). Additionally, the position of the maximum anomalies are close to the epicenter.

Let us see the dynamic mechanisms and tectonic implications of this event in order to determine whether the changes were related to the earthquake's preparation. According to Zhu et al. (2009), the occurrence of this event was because of the movement of eastward mass flow from the QinghaiTibet Plateau, and some material accumulated in the west of the Sichuan basin due to the block of the stable and strong Sichuan basin. These materials push and compress on the Longmenshan fault. When the stresses exceed the friction strength, the energy is released on a weak point (the epicenter), and then the earthquake occurs. This description looks like the characteristics of the monthly OLR variations mentioned above.

The monthly OLR grid data of 2008 nearest to the point of the epicenter were analyzed (Fig. 3). It shows that the monthly OLR variation increased distinctly from March to June, which reflects the energy accumulation for this shock. We can see the maximum variation occurred on the month of the seismic event and still continued until one month after this event. So it was discovered that the energy release for this earthquake was not rapid but slow.

Besides $2.5^{\circ}$ monthly data, $1.0^{\circ}$ daily data were analyzed using the STD (standard deviation) threshold method (Fig. 4). The details of the STD threshold method can be found in the reference (Jing et al., 2010). The period of background data is from 1 May 2006 to 30 April 2009. The results showed that the obvious OLR anomalies appeared thirteen days (29 April 2008) before the earthquake, in the epicentral area, and then appeared frequently (29-30 April, 5 May, 10 11 May) in this region until one day before the earthquake 


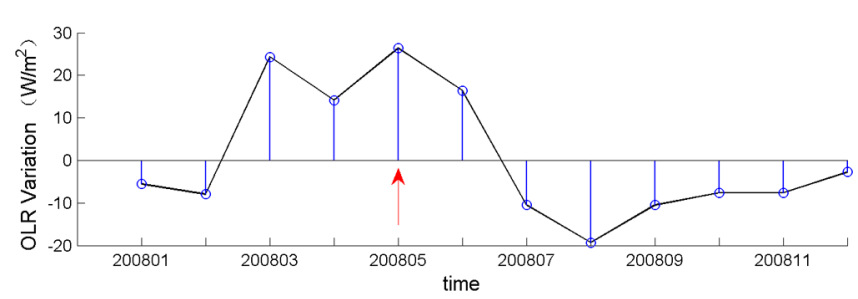

Fig. 3. Abnormal OLR evolution on the point $30^{\circ} \mathrm{N}, 102.5^{\circ} \mathrm{E}$ in 2008 (red arrow points to the month in which earthquake happened).
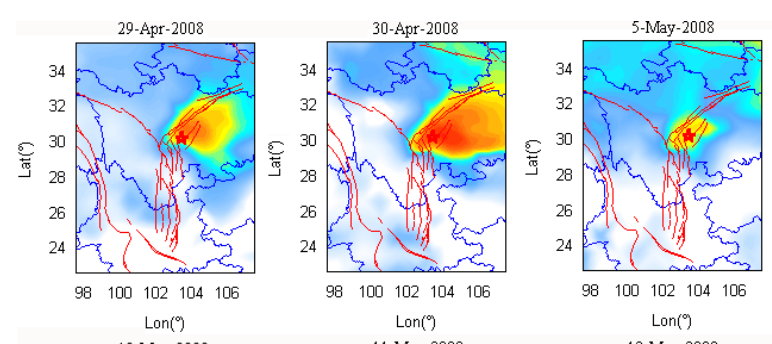

98100102104106

Lon( $(\%)$
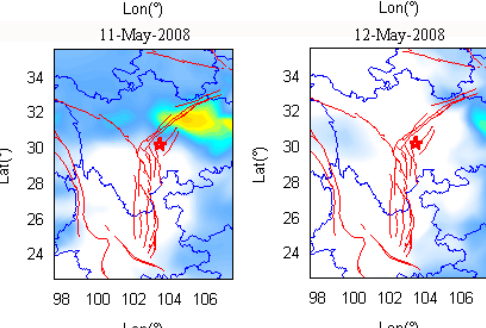

Lon $(9$

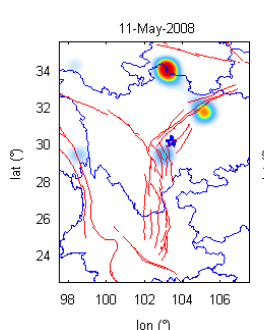

$\operatorname{lon}\left(0^{\circ}\right.$
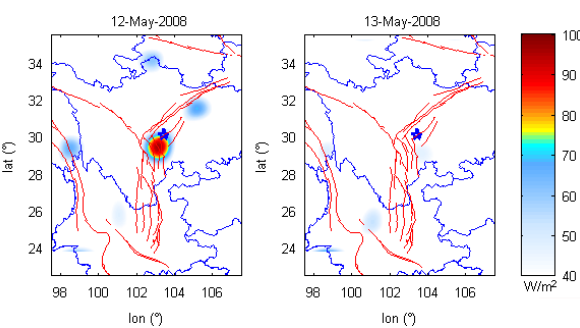

lon $(9)$

Fig. 5. The daily SLHF anomaly evolution for the Wenchuan $M_{\mathrm{S}}=$ 8.0 earthquake (epicenter is marked with star, active faults with red lines).

earthquake. The maximum variation was observed on the seismic shock day and the value exceeded $100 \mathrm{~W} \mathrm{~m}^{-2}$. The position of SLHF anomaly was very close to the epicenter. The anomalies disappear after the shock (Fig. 5).

\subsection{Air temperature (AT), air pressure (AP), and air relative humidity $(\mathrm{ARH})$}

Air temperature (AT), air pressure (AP), and air relative humidity (ARH) are important meteorological parameters. The abnormal variations of AT, ARH, and AP, before earthquakes have been reported (Pulinets et al., 2005, 2006a, b, 2007; Ma et al., 1982) based on the observations of the ground stations. AT, AP, and ARH data used in our research are acquired by comprehensive observations on multi-source platforms such as ground station, ship, satellite, and others in the NCEP/NCAR Reanalysis Project, which has a strict quality control system to ensure the data credibility.

The ten-year AT and ARH data from 1998 to 2007 have been selected as background data in order to obtain the variation related to the Wenchuan earthquake. We found that the point $\left(30^{\circ} \mathrm{N}, 105^{\circ} \mathrm{E}\right)$ east of the Longmenshan fault showed the high value in AT and the low value in ARH by comparing the data of 2008 to the background data. This point is located very close to the epicenter in the grid dataset. Is it a precursor to this event?

Then we focused on this point and studied the variation feature about it. The long time series of AT monthly data in May, from 1970 to 2009, have been analyzed (Fig. 6). The result indicated that the monthly mean value in the year of 2008 was the maximum and reached up to $21.93^{\circ} \mathrm{C}$ during the 39 -yr period, which is higher $2.4^{\circ} \mathrm{C}$ than the average in these years. We speculated this behavior has a relationship with the Wenchuan earthquake.

Similarly, we analyzed ARH variation pre- and postearthquake based on ten-year data, from 1998 to 2007. The results are shown in Fig. 7. One can see that higher AT and the lowest ARH appeared together ten days and one day before this earthquake, which is possibly a precursor signal to this earthquake because the similar phenomenon has been reported in the Michoacan $M=8.1$ earthquake by Pulinets et al. (2007). 


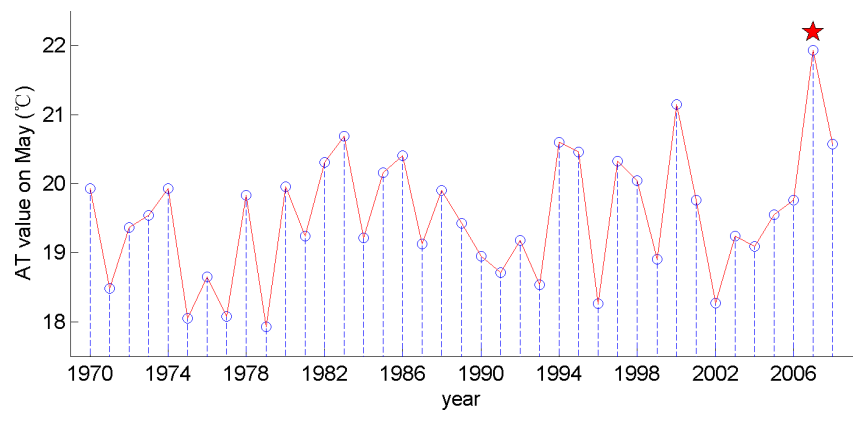

Fig. 6. Air temperature variation in May, from 1970 to 2009, at the point $30^{\circ} \mathrm{N}, 105^{\circ} \mathrm{E}$ (red star points to the year in which earthquake happened).

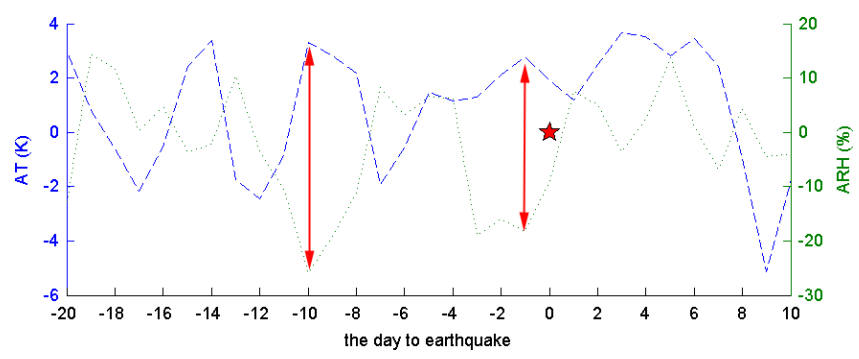

Fig. 7. Air temperature and relative humidity variation at the point $30^{\circ} \mathrm{N}, 105^{\circ} \mathrm{E}$ before and after the event (red star points to the day in which earthquake happened).

Besides AT and ARH, the variation of air pressure during the same period have been analyzed. The results are presented in Fig. 8. We can see there are two obvious variations before the event. The first variation appears from fourteen days to seven days before the event. The second is from seven days to two days prior to the event. They all drop initially and then rise. The lowest pressure value during this period was $932 \mathrm{hPa}$, which is lower than the average value of $10 \mathrm{hPa}$.

The variation of $\mathrm{AT}, \mathrm{ARH}$, and $\mathrm{AP}$ on the basin point $30^{\circ} \mathrm{N}, 105^{\circ} \mathrm{E}$ have been analyzed above. And how is the mountainous point? We also analyzed the mountainous point $30^{\circ} \mathrm{N}, 102.5^{\circ} \mathrm{E}$ that is closest to the epicenter. From the differential map between basin point $\left(30^{\circ} \mathrm{N}, 105^{\circ} \mathrm{E}\right)$ and mountainous point $\left(30^{\circ} \mathrm{N}, 102.5^{\circ} \mathrm{E}\right)$, regarding $\mathrm{AT}$ and $\mathrm{ARH}$, one can see that the variation on mountain area and basin area of AT and ARH are almost in synchrony from 2 May $(-10 \mathrm{~d})$ to 11 May ( $-1 \mathrm{~d}$ ) (Fig. 9). The similar variations of AP are observed on the mountain. AP has two sudden drops and the time is the same as at the basin point. The only difference is the descending range is smaller (Fig. 10).

\section{Discussion}

In this paper, the variations of OLR, SLHF, AT, ARH, and AP related to the Wenchuan earthquake have been analyzed. In addition, we obtained the variation of radon related to this

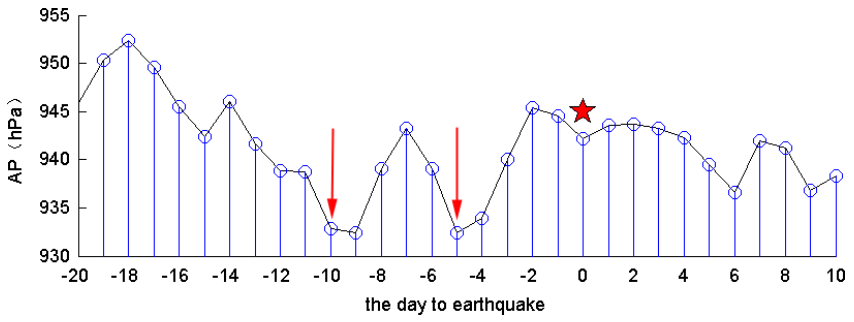

Fig. 8. Air pressure variation at the point $30^{\circ} \mathrm{N}, 105^{\circ} \mathrm{E}$ before and after the event (red star points to the day in which earthquake happened).

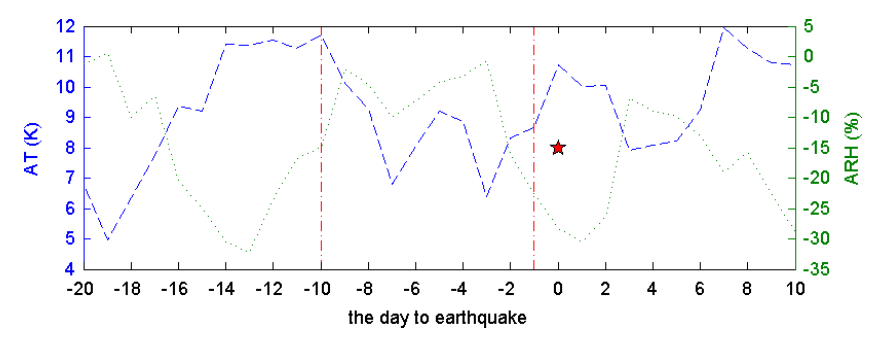

Fig. 9. The difference between the basin point $\left(30^{\circ} \mathrm{N}, 105^{\circ} \mathrm{E}\right)$ and the mountain point $\left(30^{\circ} \mathrm{N}, 102.5^{\circ} \mathrm{E}\right)$ in air temperature and relative humidity (red star points to the day in which earthquake happened).

earthquake in the reference (Liu et al., 2008). The variations of multi-parameters are be listed in Table 1. One can see that OLR anomalies are observed firstly. Next are the abnormal variations of AT, ARH, AP and radon, which occurred almost at the same time. Lastly are the SLHF abnormal variations. Did these variations have a relationship with Wenchuan earthquake? Let us give a further analysis.

Firstly let us pay attention to OLR. OLR is a crucial atmospheric parameter which can reflect the radiation on the top of the atmosphere. A lot of case studies (Liu et al., 1997, 2000, 2003; Ouzounov et al., 2007; Kang et al., 2008; Jing et al., 2009; and Xiong et al., 2010) have proved that OLR is an effective parameter for seismic short-term monitoring. Especially, the variation of OLR was associated with the seismogenic structure, which can be seen in several case studies (Jing et al., 2010). In this study, OLR monthly variations showed that the energy accumulated along the west of the Sichuan basin and was then released close to the epicenter. Daily OLR variation also indicated that the energy accumulation occurred in the Longmenshan fault zone, which is the seismogenic structure. This relationship allows us to think that it is a precursor signal of the seismic preparation, especially, which can provide some information on the activity of seismic structures.

Next are AT, ARH, AP, and radon. The variations of AT and ARH are obtained by subtracting the mean value of the years 1998-2007. The lowest ARH accompanied higher AT, which can be regarded as a seismic anomaly according to previous studies (Dunajecka et al., 2005; Pulinets et al., 
Table 1. The variation characteristics of earth-atmosphere system multi-parameters before and after the Wenchuan earthquake.

\begin{tabular}{llcc}
\hline Parameters & $\begin{array}{l}\text { Abnormal } \\
\text { feature }\end{array}$ & $\begin{array}{c}\text { Time of anomaly } \\
\text { occurrence (day) }\end{array}$ & $\begin{array}{c}\text { Time of anomaly } \\
\text { disappearance (day) }\end{array}$ \\
\hline OLR & increase & -13 & +1 \\
SLHF & increase & -1 & +1 \\
AT & increase, corresponding to the lowest value of ARH & -10 and -1 & +1 \\
ARH & decrease, corresponding to higher value of AT & -10 and -1 & +1 \\
AP & sudden drop & -10 and -5 & -2 \\
Gas (Rn) & increase & -10 and -2 & +1 \\
\hline
\end{tabular}

“-”:pre-earthquake, “+”:post-earthquake

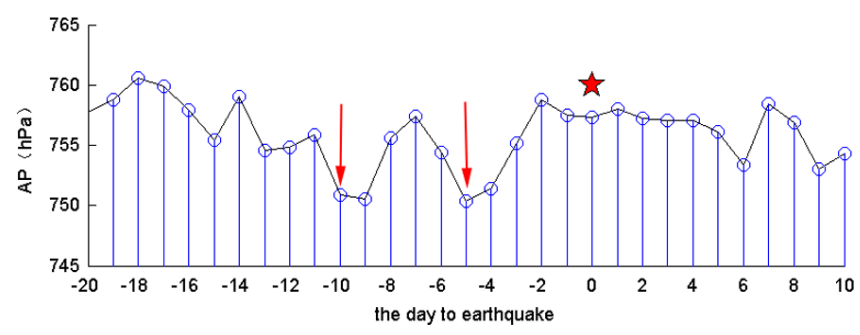

Fig. 10. Air pressure variation at the mountain point $30^{\circ} \mathrm{N}, 102.5^{\circ} \mathrm{E}$ before and after the event (red star points to the day in which earthquake happened).

2006). They think it is a result of radon activity, and in this case the radon anomaly was also observed on the same day (Liu et al., 2008). This radon anomaly was observed by the ground station which is $1800 \mathrm{~km}$ from the epicenter. It does not ruled out that this anomaly was related to this event, as a result of the far-field effect of a strong earthquake (Cheng, 1997).However, whether the variations of AT and ARH were caused by radon cannot be determined. As for AP, it has two dramatic variations before this event. Although there is no clear evidence that the variation in air pressure can trigger earthquakes, but several results (Ma et al., 1982) have shown that the air pressure may be one of the trigger factors for earthquake occurrence. The variations of AP before the Tonghai $M=7.7$ earthquake of 1970 and the Tangshan $M=7.8$ earthquake of 1976 in China, shown in Fig. 11, are similar to our result from the Wenchuan earthquake. This made us speculate that AP variation may trigger earthquake activity in the case of the fault stress closing to the critical state. In this case, the variations of AT, ARH, and AP show quasi-synchronous both in the basin and the mountain area close to the epicenter from ten days to one day before the Wenchuan earthquake. It can be speculated that one factor controlled and influenced the regional atmosphere during this period. Considering some similar phenomena found in other earthquakes (Pulinets et al., 2006a, b, 2007), we believe that these changes may be associated with the preparation of the Wenchuan earthquake.

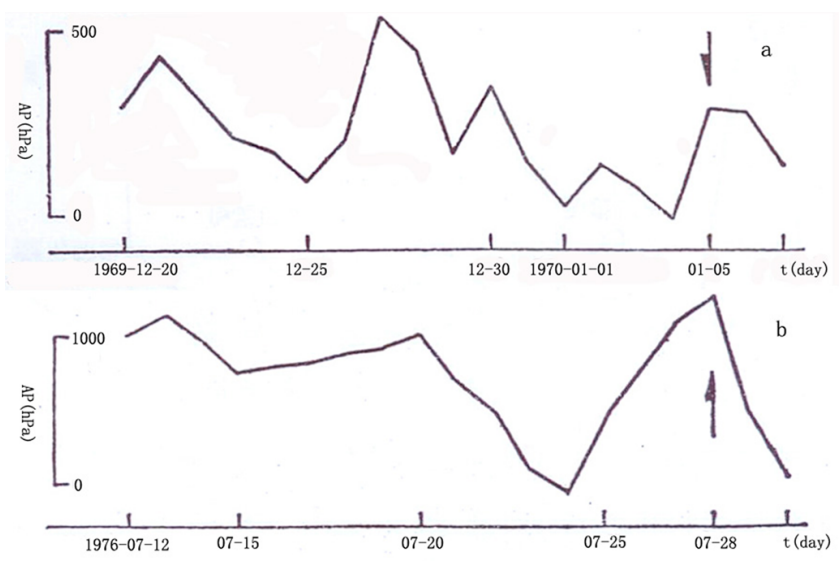

Fig. 11. Air pressure variation related to strong earthquakes (Ma et al., 1982). (a) Tonghai earthquake $M=7.7$ of 5 January 1970, (b) Tangshan earthquake $M=7.8$ of 28 July 1978 (arrow points to the day in which earthquake happened).

The third is SLHF. SLHF anomalies have been detected in some coastal earthquakes such as the Gujarat earthquake of 26 January 2001, Colima earthquake of 22 January 2003, Tokachi-Oki earthquake of 25 September 2003, Sumatra earthquake of 26 December 2004, and so on (Dey et al., 2003; Cervone et al., 2005; Cervone et al., 2006; and Singh et al., 2007). Recent studies have shown that there is some relationship between SLHF anomalies and soil moisture (Qin et al., 2012). Therefore, SLHF anomalies may occur in the intraplate earthquakes. In this event SLHF anomalies appear one day before the shock. We do not rule out the possibility that this variation is a seismic anomaly.

Finally, let us see what kind of relationship exists between the parameters mentioned above during the process of earthquake preparation. Maybe it can be explained by the Lithosphere-Atmosphere-Ionosphere Coupling (LAIC) model (Pulinets et al., 2011). According to the LAIC model, the release of radon is the main source of atmospheric parameter variations. The increase of radon release makes the air ionization. Next, the water molecules attach to the newly formed ions and release the latent heat, which leads to the increased anomalous flux of the latent heat and drop in air 
relative humidity. This is consistent with the phenomenon we observed. However, we consider other geochemical gases besides radon cannot be ignored in the process of thermal variation. The reason is radon cannot migrate to the surface by itself in a short time due to the physical properties of radon. $\mathrm{CO}, \mathrm{CO}_{2}, \mathrm{CH}_{4}$, and other geochemical gases play important roles in the process of radon emission into the atmosphere (Martinelli et al., 1991; Du et al., 2008). The anomalies of geochemical gases over the seismic fault zone were found based on the field measurements after this event (Zhou et al., 2010). The tectonic stress increases during the period of earthquake preparation, resulting in a large number of microfractures. Radon migrates upwards to the surface, carried by $\mathrm{CO}, \mathrm{CO}_{2}, \mathrm{CH}_{4}$ and other geochemical gases in a short time, along the micro-fractures and the faults. So we think that these geochemical gases have contributed greatly during this process.

\section{Conclusions}

Earthquake preparation occurred in a broad regional tectonic and seismogenic system. The complicated geodynamic and tectonic-physical processes, and the epicenter condition, make the seismic preparation complex. The variations of tectonic movement exist all the time, which make the seismic anomalies appear in a large region and over a long time. This is the physical basis on seismic precursor study.

Only one parameter has limitations in reflecting the complex seismic preparation process. The comprehensive analysis of multi-parameters may effectively enhance the reliability of abnormal activity identification. The satellite observations provided an opportunity for quick access to numerous precursor signals over the seismogenic zone. The analyses on multi-parameters (OLR, SLHF, AT, ARH, and AP) of the Wenchuan earthquake demonstrate that there are significant variations in these parameters before the occurrence of this event. The variations can be attributed to solid earth degassing and chemical reactions in the atmosphere, owing to the seismic and tectonic stress.

Earthquake prediction is still a challenging work to us. Much work needs to be done in how to obtain the seismic precursor information. The different ways, such as spacebased and ground-based comprehensive observations are an important directions to earthquake monitoring in the future.

Acknowledgements. This research was supported by the International Science and Technology Cooperation Program of China (2010DFB20190). The authors would like to thank the National Center for Atmospheric Research providing OLR data, and the National Centers for Environmental Prediction providing SLHF, air temperature, air pressure, and air relative humidity data for this work. The authors also acknowledge Jianguo Du for discussion on geochemical anomalies to seismic activity, S. Pulinets and the two reviewers for detailed comments in improving this manuscript.
Edited by: M. E. Contadakis

Reviewed by: S. Pulinets and two anonymous referees

\section{References}

Cervone, G., Singh, R. P., Kafatos, M., and Yu, C.: Wavelet maxima curves of surface latent heat flux anomalies associated with Indian earthquakes, Nat. Hazards Earth Syst. Sci., 5, 87-99, doi:10.5194/nhess-5-87-2005, 2005.

Cervone, G., Kafatos, M., Napoletani, D., and Singh, R. P.: An early warning system for coastal earthquakes, Adv. Space Res., 37, 636-642, 2006.

Cervone, G., Maekawa, S., Singh, R. P., Hayakawa, M., Kafatos, M., and Shvets, A.: Surface latent heat flux and nighttime LF anomalies prior to the $M_{\mathrm{W}}=8.3$ Tokachi-Oki earthquake, Nat. Hazards Earth Syst. Sci., 6, 109-114, doi:10.5194/nhess-6-1092006, 2006.

Cheng, S.: Primary probe about both premonitory far-field effect of strong earthquake and possible causes of formation, Earthq. Res. Sichuan, 4, 15-21, 1997 (in Chinese with English abstract).

Dey, S. and Singh, R. P.: Surface latent heat flux as an earthquake precursor, Nat. Hazards Earth Syst. Sci., 3, 749-755, doi:10.5194/nhess-3-749-2003, 2003.

Du, J., Si, X., Chen, Y., Fu, H., Jian, C., and Guo, W.: Geochemical anomalies connected with great earthquakes in China, Geochemistry Research Advances, New York, Nova Science Publishers, Inc, 57-92, 2008.

Dunajecka, M. and Pulinets, S.: Atmospheric and thermal anomalies observed around the time of strong earthquakes in Mexico, Atmósfera, 18, 235-247, 2005.

Jing, F.: Study on Seismic Anomalous Features in Outgoing Longwave Radiation based on Background Fields Analysis, doctoral dissertation, Beijing graduate university of Chinese academy of sciences, 2010 (in Chinese with English abstract).

Jing, F., Shen, X. H, Kang, C. L., Meng, Q. Y., and Xiong, P.: Anomalies of Outgoing Longwave Radiation before some medium to large earthquakes, Earthquakes, 29, 117-122, 2009 (in Chinese with English abstract).

Jing, F., Shen, X., Kang, C., Meng, Q., Chen, Y., and Hong, S.: Extracting seismic anomalies based on std threshold method using outgoing longwave radiation data, IGARSS2010, 1561-1564, 2010.

Kang, C. L, Han, Y. B, Liu, D. F, and Cao,Z. Q.: The OLR anomaly and mechanism before Tibet earthquake M6.9, Progress Geophys., 6, 1703-1708, 2008 (in Chinese with English abstract).

Liebmann, B.: Description of a complete (interpolated) outgoing longwave radiation dataset, Bull. Amer. Meteor. Soc., 77, 12751277, 1996.

Liu, D. F.: Abnormal detection on satellite remote sensing OLR before ChiChi earthquakes, Geo-Inf. Sci., 1, 33-36, 2000 (in Chinese with English abstract).

Liu, D. F. and Kang, C. L.: Predicting heavy disasters by Outgoing Longwave Radiation (OLR) of the earth, Earth Sci. Front., 10, 427-434, 2003 (in Chinese with English abstract).

Liu, D. F., Luo, Z. L., and Peng, K. Y.: OLR anomalous phenomena before strong earthquakes, Earthquake, 17, 126-132, 1997 (in Chinese with English abstract). 
Liu, D. Y.: Discussion on relation between anomalies of water temperature and radon in Ningbo station and Wenchuan Ms 8.0 earthquake, J. Geodesy Geodynam., 28, 53-55, 2008 (in Chinese with English abstract).

Liu, J. Y., Chuo, Y. J., Shan, S. J., Tsai, Y. B., Chen, Y. I., Pulinets, S. A., and Yu, S. B.: Pre-earthquake ionospheric anomalies registered by continuous GPS TEC measurements, Ann. Geophys., 22, 1585-1593, doi:10.5194/angeo-22-1585-2004, 2004.

Ma, Z. J., Fu, Z. X., Zhang, Y. Z., Wang, C. M., Zhang, G. M., and Liu, D. F.: Nine strong earthquakes in China from 1966 to 1976, Beijing, Seismological Press, 117-119, 1982 (in Chinese).

Martinelli, G. and Ferrari, G.: Earthquake forerunners in a selected area of Northern Italy: recent developments in automatic geochemical monitoring, Tectonophysics, 193, 397-410, 1991.

Ouzounov, D., Liu, D., Chunli, K., Cervone, G., Kafatos, M., and Taylor, P.: Outgoing long wave radiation variability from IR satellite data prior to major earthquakes, Tectonophysics, 431, 211-220, 2007.

Panda, S. K., Choudhury, S., Saraf, A. K., and Das, J. D.: MODIS land surface temperature data detects thermal anomaly preceding 8 October 2005 Kashmir earthquake, Int. J. Remote Sens., 28, 4587-4596, 2007.

Pulinets, S. A. and Dunajecka, M. A.: Specific variations of air temperature and relative humidity around the time of Michoacan earthquake M8.1 Sept. 19, 1985 as a possible indicator of interaction between tectonic plates, Tectonophysics, 431, 221-230, 2007.

Pulinets, S. A. and Ouzounov, D.: Lithosphere-AtmosphereIonosphere Coupling (LAIC) model-An unified concept for earthquake precursors validation, J. Asian Earth Sci., 41, 371382, 2011.

Pulinets, S. A., Ouzounov, D., Karelin, A. V., Boyarchuk, K. A., and Pokhmelnykh, L. A.: The physical nature of thermal anomalies observed before strong earthquakes, Phys. Chem. Earth, 31, 143153, 2006a.
Pulinets, S. A., Ouzounov, D., Ciraolo, L., Singh, R., Cervone, G., Leyva, A., Dunajecka, M., Karelin, A. V., Boyarchuk, K. A., and Kotsarenko, A.: Thermal, atmospheric and ionospheric anomalies around the time of the Colima M7.8 earthquake of 21 January 2003, Ann. Geophys., 24, 835-849, doi:10.5194/angeo-24-8352006, 2006b.

Qin, K., Wu, L. X., De Santis, A., Meng, J., Ma, W. Y., and Cianchini, G.: Quasi-synchronous multi-parameter anomalies associated with the 2010-2011 New Zealand earthquake sequence, Nat. Hazards Earth Syst. Sci., 12, 1059-1072, doi:10.5194/nhess-121059-2012, 2012.

Singh, R. P., Cervone, G., Kafatos, M., Prasad, A. K., Sahoo, A. K., Sun, D., Tang, D. L., and Yang, R.: Multi-sensor studies of the Sumatra earthquake and tsunami of 26 December 2004, Int. J. Remote Sens., 28, 2885-2896, 2007.

Smith, S. R., Legler, D. M., and Verzone, K. V.: Quantifying uncertainties in NCEP reanalyses using high-quality research vessel observations, J. Climate, 14, 4062-4072, 2001.

Tronin, A., Biagi, P., Molchanov, O., Khatkevich, Y., and Gordeev, E.: Temperature variations related to earthquakes from simultaneous observation at the ground stations and by satellites in Kamchatka area, Phys. Chem. Earth, 29, 501-506, 2004.

Xiong, P., Shen, X. H., Bi, Y. X., Kang, C. L., Chen, L. Z., Jing, F., and Chen, Y.: Study of outgoing longwave radiation anomalies associated with Haiti earthquake, Nat. Hazards Earth Syst. Sci., 10, 2169-2178, doi:10.5194/nhess-10-2169-2010, 2010.

Zhou, X., Du, J., Chen, Z., Cheng, J., Tang, Y., Yang, L., Xie, C., Cui, Y., Liu, L., and Yi, L.: Geochemistry of soil gas in the seismic fault zone produced by the Wenchuan Ms 8.0 earthquake,southwestern China, Geochem. Trans., 11, doi:10.1186/1467-4866-11-5, 2010.

Zhu, S. B. and Zhang, P. Z.: A study on the dynamical mechanisms of the Wenchuan Ms8.0 earthquake, 2008, Chinese J. Geophys., 52, 418-427, 2009 (in Chinese with English abstract). 